\title{
Diagnóstico da sustentabilidade de propriedades rurais produtoras de leite na microbacia do arroio da seca
}

A produção leiteira tem papel importante na economia brasileira e gaúcha, gerando importantes retornos em impostos e na geração de renda em 205.158 estabelecimentos rurais, acrescidos ainda dos demais empregos da cadeia produtiva. No Vale do Taquari, a produção leiteira em pequenas propriedades rurais também desempenha importante papel socioeconômico, entretanto, repercute com impactos ambientais como a erosão e a contaminação das águas. Este trabalho teve como objetivo diagnosticar a sustentabilidade ambiental de propriedades rurais produtoras de leite localizadas na microbacia do Arroio da Seca, no Rio Grande do Sul, buscando incluir dados da vegetação nativa ocorrente. Utilizaram-se entrevistas, vistorias, análise de imagens de satélite e levantamento fitossociológico da vegetação arbórea para a obtenção dos dados. Estes dados foram tabulados em planilha eletrônica e analisados por meio de estatística descritiva. Constataram-se inadequações no manejo dos dejetos, sinais de erosão, invasão de áreas de preservação permanente e armazenamento irregular de agrotóxicos. Seis propriedades foram consideradas com sustentabilidade 'regular', cinco com 'boa' e uma com 'ruim'. Neste estudo, houve correlação média positiva, porém não significativa entre o índice de diversidade de Shannon e a pontuação de sustentabilidade. Onze propriedades se enquadraram como tendo excelente diversidade arbórea. Propõe-se a criação de software de diagnóstico de sustentabilidade para agilizar a análise e minimizar a subjetividade.

Palavras-chave: Impacto Ambiental; Bovinocultura; Relação Biodiversidade-Sustentabilidade; Software de Diagnóstico Ambiental.

\section{Diagnosis of the sustainability of rural milk producing properties in dry rice microbacy}

\begin{abstract}
Milk production plays an important role in the Brazilian and Rio Grande do Sul economy, generating important returns in taxes and income generation in 205,158 rural establishments, plus other jobs in the production chain. In the Vale do Taquari, dairy production in small farms also plays an important socioeconomic role, however, it has repercussions on environmental impacts such as erosion and water contamination. This work aimed to diagnose the environmental sustainability of rural dairy farms located in the Arroio da Seca, watershed, in the State of Rio Grande do Sul, Brazil, aiming to include data from the native vegetation. Interviews, visits, satellite image analysis and phytosociological survey of tree vegetation were used to obtain the data, which were tabulated in a spreadsheet. There were problems in the management of manure, signs of erosion, invasion of permanent preservation areas and irregular storage of agrochemicals. Six properties were considered with 'regular' sustainability, as well as five as 'good' and one as 'bad'. In this study, there was a positive but non-significant correlation between the Shannon diversity index and the sustainability score. Eleven properties were classified as having excellent tree species diversity. It is proposed to create a diagnostic software to expedite analysis and minimize subjectivity.
\end{abstract}

Keywords: Environmental Impact; Cattle Breeding; Biodiversity-Sustainability Relation; Environmental Diagnostic Software.

Topic: Engenharia Ambiental

Reviewed anonymously in the process of blind peer
Received: $14 / 12 / 2017$

Approved: 24/01/2018
Cristian Mateus Zerwes (ib)

Universidade do Vale do Taquari, Brasil http://lattes.cnpq.br/9316007567169561

http://orcid.org/0000-0002-1503-2780

cristianzerwes@universo.univates.br

\section{Claudete Rempel (iD)}

Universidade do Vale do Taquari, Brasil

http://lattes.cnpq.br/8340497822227462

http://orcid.org/0000-0001-8573-0237

crempel@univates.br

Gustavo Rodrigo da Silva

Universidade do Vale do Taquari, Brasil

http://lattes.cnpq.br/4580848075797987

gustavo.silva1@univates.br

DOI: $10.6008 / C B P C 2179-6858.2018 .002 .0019$

\section{Referencing this:}

ZERWES, C. M.; REMPEL, C.; SILVA, G. R.. Diagnóstico da sustentabilidade de propriedades rurais produtoras de leite na microbacia do arroio da seca. Revista Ibero Americana de Ciências Ambientais, v.9, n.2, p.218-230, 2018. DOI: http://doi.org/10.6008/CBPC2179-6858.2018.002.0019 


\section{INTRODUÇÃO}

A produção leiteira tem papel importante na economia brasileira e gaúcha, gerando importantes retornos em impostos e na geração de renda em 205.158 estabelecimentos rurais, acrescidos ainda dos demais empregos da cadeia produtiva, conforme dados do último censo agropecuário (IBGE, 2006). Na área de estudo, na microrregião do Vale do Taquari, centro-leste do Rio Grande do Sul, a produção leiteira representa a base da economia da maioria das pequenas propriedades rurais (REMPEL et al., 2012). Além disso, o leite é fundamental para a alimentação humana, pois é um conjunto físico-químico complexo e altamente nutritivo (PACCALIN et al., 1985).

Contudo, a pecuária é uma contribuinte dos mais graves problemas ambientais, em todos os níveis, do local ao global, incluindo degradação do solo, mudanças climáticas, poluição do ar, contaminação da água por dejetos e perda de biodiversidade (SCREMIN et al., 2010; REMPEL et al., 2012). Mas ao invés de banir esta atividade com importantes retornos socioeconômicos, pode-se implementar melhorias nas propriedades rurais para incrementar a sustentabilidade das mesmas, entretanto, é fundamental avaliar a situação atual, para então embasar a futura escolha de medidas a serem implantadas (RODRIGUES et al., 2003). Neste viés, Rempel et al. (2012) propuseram um método de avaliação de sustentabilidade de propriedades produtoras de leite na microrregião do Vale do Taquari, mediante uso de entrevista, vistoria in loco e mapeamento do uso do solo.

Pode-se também acrescentar às pontuações de sustentabilidade, dados de biodiversidade e fitossociológicos da vegetação ocorrente nas propriedades, pois ela provê serviços ambientais como a conservação das águas superficiais, a polinização e a manutenção da estabilidade geológica e pedológica (FISZON, 2003). Dentre estudos que seguiram tal linha, citam-se o de Vecchione (2010), que incluiu o Índice de Diversidade de Shannon $\left(H^{\prime}\right)$, num cálculo de pontuação de sustentabilidade para propriedades agrícolas no sul da Itália; Markus (2014), que propôs a utilização do $\mathrm{H}^{\prime}$ do estrato arbóreo, para avaliar propriedades produtoras de leite, no Vale do Taquari, e Zerwes (2016), que demonstrou a correlação forte positiva entre H' e o índice de sustentabilidade calculado numa adaptação dos parâmetros de Rempel et al. (2012), também em propriedades que produzem leite, na microbacia do Arroio da Seca, Imigrante e Colinas/RS. Neste sentido, o estudo objetiva diagnosticar a sustentabilidade ambiental de propriedades rurais produtoras de leite existentes na Microbacia do Arroio da Seca, Rio Grande do Sul/Brasil, buscando incluir dados da vegetação nativa ocorrente nas propriedades em tal diagnóstico.

\section{MATERIAIS E MÉTODOS}

A área de estudo (Figura 1), Microbacia do Arroio da Seca, está inserida na bacia hidrográfica do Rio Taquari-Antas. Conforme o IBGE (2003; 2012), a vegetação ocorrente é a Floresta Estacional Decidual, havendo duas formações, a submontana (até $400 \mathrm{~m}$ de altitude) e a montana (acima de $400 \mathrm{~m}$ ). A bacia se situa na encosta da Serra Geral, ocorrendo basaltos da Formação Serra Geral e arenitos intertrápicos da Formação Botucatu (CPRM, 2006). Os solos são classificados, conforme o INDE (2016), como associações de 
nitossolo vermelho eutroférrico típico e chernossólico, nitossolo vermelho eutroférrico latossólico e neossolo litólico eutrófico típico. O clima da região é o subtropical Cfa com temperatura e precipitação anual média de $18^{\circ} \mathrm{C}$ e $1.600 \mathrm{~mm}$, respectivamente (CIH-UNIVATES, 2012).

Este estudo é parte integrante do Grupo de Pesquisa em Avaliação da Sustentabilidade Ambiental de Propriedades Produtoras de Leite no Vale do Taquari, que avalia a sustentabilidade de 104 propriedades da região do Vale do Taquari/RS. Para a consecução do presente, foi definida uma amostra de 12 propriedades rurais distribuídas ao longo da porção submontana da microbacia, nos municípios de Imigrante e Colinas/RS, de acordo com a metodologia descrita em Zerwes (2016). Cabe mencionar que Imigrante/RS possui 3.123 habitantes, área de 73,35 km², IDH 0,743 e 2.022 vacas ordenhadas em 324 propriedades rurais; já Colinas/RS, 2.420 habitantes, área de 58,37 km² $^{2}$ IDH 0,765 e 1.720 vacas ordenhadas em 198 propriedades rurais (IBGE, 2014).

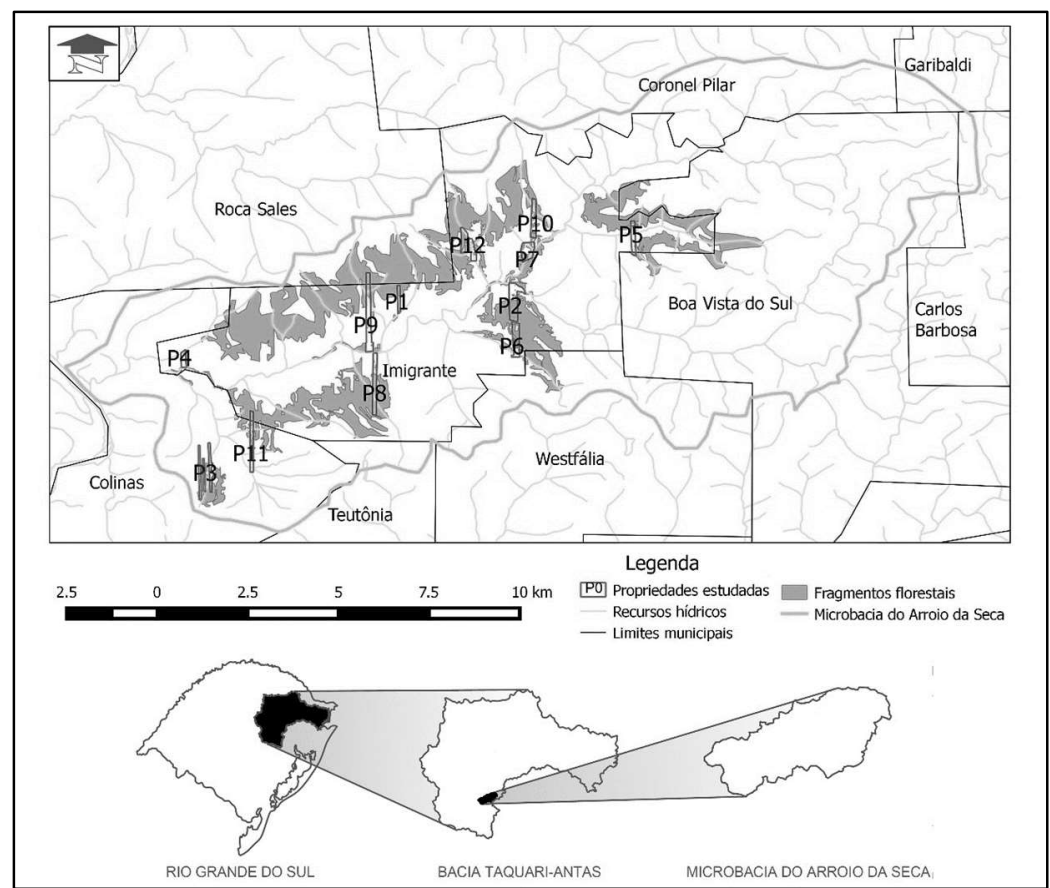

Figura 1: Mapa da microbacia do Arroio da Seca, com a indicação das 12 propriedades estudadas. Fonte: Ministério do Exército (1980). Desenho: Cristian Mateus Zerwes, elaborado no Quantum GIS Lyon e Autocad.

Cada propriedade foi visitada pelo grupo de pesquisa, onde se realizaram as entrevistas, vistorias e mapeamento dos usos do solo, conforme metodologia de Rempel et al. (2012), estudo que também embasou os cálculos do índice de sustentabilidade, conforme pontuações atribuídas à diversos parâmetros apresentados na

Os dados quantitativos obtidos foram tabulados em planilha eletrônica, tendo calculadas suas média e desvio-padrão $(\sigma)$, bem como plotados seus respectivos gráficos (as propriedades estão apresentadas na sequência do menor para o maior rebanho de gado). Os mapas de uso do solo foram elaborados no Autocad, com base em imagens de satélite de alta resolução obtidas no Google Earth, aliadas às informações dos proprietários e vistorias, aonde coletou-se pontos com GPS (Sistema de Posicionamento Global). O Past 2.17c (HAMMER et al., 2001) foi utilizado para comparar diferentes variáveis entre as propriedades estudadas e verificar quais delas se correlacionavam, através do método da correlação linear $r$. 
Tabela 1. Além disso, cada propriedade recebeu o levantamento da vegetação arbórea nativa, seja na reserva legal (RL) ou nas áreas de preservação permanente (APP), cuja metodologia e resultados florísticosfitossociológicos são parte integrante da Dissertação do primeiro autor (ZERWES, 2016).

Os dados quantitativos obtidos foram tabulados em planilha eletrônica, tendo calculadas suas média e desvio-padrão $(\sigma)$, bem como plotados seus respectivos gráficos (as propriedades estão apresentadas na sequência do menor para o maior rebanho de gado). Os mapas de uso do solo foram elaborados no Autocad, com base em imagens de satélite de alta resolução obtidas no Google Earth, aliadas às informações dos proprietários e vistorias, aonde coletou-se pontos com GPS (Sistema de Posicionamento Global). O Past 2.17c (HAMMER et al., 2001) foi utilizado para comparar diferentes variáveis entre as propriedades estudadas e verificar quais delas se correlacionavam, através do método da correlação linear $r$.

Tabela 1: Parâmetros e subparâmetros e suas respectivas pontuações utilizadas para aferir o índice de sustentabilidade das propriedades.

\begin{tabular}{|c|c|}
\hline Parâmetro / Subparâmetro & $\begin{array}{l}\text { Pontuação } \\
\text { atribuída }\end{array}$ \\
\hline PARÂMETRO DEJETOS & 30 \\
\hline 1.1 Subparâmetro de armazenamento do dejeto sólido & 10 \\
\hline Estrumeira fechada e coberta & 10 \\
\hline Estrumeira fechada e sem cobertura & 7 \\
\hline Sem estrumeira & 3 \\
\hline Liberação do dejeto próximo a curso hídrico & 0 \\
\hline 1.2 Subparâmetro de armazenamento do dejeto líquido & 10 \\
\hline Tratamento total do efluente gerado e posterior liberação em curso hídrico & 10 \\
\hline Estrumeira fechada e coberta & 7,5 \\
\hline Estrumeira fechada e sem cobertura & 5 \\
\hline Sem estrumeira & 2,5 \\
\hline Liberação do efluente próximo a curso hídrico & 0 \\
\hline 1.3 Subparâmetro de destinação do dejeto animal & 10 \\
\hline Aplicação balanceada e longe dos recursos hídricos & 10 \\
\hline Aplicação conforme disponibilidade de dejeto & 5 \\
\hline Aplicação do dejeto sem controle & 0 \\
\hline 2. PARÂMETRO APP & 15 \\
\hline 2.1 Subparâmetro percentual de utilização antrópica das APPs & 10 \\
\hline s & 10 \\
\hline 1 a $30 \%$ & 7,5 \\
\hline 31 a $55 \%$ & 5 \\
\hline 56 a $80 \%$ & 2,5 \\
\hline 81 a $100 \%$ & 0 \\
\hline 2.2 Subparâmetro do uso predominante na APP & 5 \\
\hline Mata Nativa & 5 \\
\hline Culturas permanentes e mata exótica & 4 \\
\hline Áreas de pastagem & 3 \\
\hline Agricultura & 2 \\
\hline Benfeitorias & 1 \\
\hline 3. PARÂMETRO AGROTÓXICOS E FERTILIZANTES & 15 \\
\hline 3.1 Subparâmetro utilização de fertilizantes químicos e agrotóxicos & 10 \\
\hline Sem utilização & 10 \\
\hline Aplicação controlada & 7,5 \\
\hline Aplicação em toda a propriedade exceto em proximidades de poços, córregos e benfeitorias & 5 \\
\hline Aplicação sem controle em toda a propriedade & 2,5 \\
\hline Aplicação sem controle e próximo aos cursos de água & 0 \\
\hline 3.2 Subparâmetro armazenamento de embalagens de agrotóxicos & 5 \\
\hline $\begin{array}{l}\text { Em depósito especial coberto, separado de qualquer medicamento, alimento, animal e salvo de umidade ou } \\
\text { não utiliza agrotóxicos }\end{array}$ & 5 \\
\hline Em depósito coberto & 3 \\
\hline Em qualquer local da propriedade & 2 \\
\hline
\end{tabular}




\begin{tabular}{|c|c|}
\hline Descartado sem cuidado & 0 \\
\hline 4. PARÂMETRO RESERVA LEGAL & 10 \\
\hline 4.1 Subparâmetro percentual de vegetação nativa para averbação em reserva legal & 10 \\
\hline Área de reserva legal superior a $20 \%$ & 10 \\
\hline 15 a $20 \%$ de área de reserva legal & 7,5 \\
\hline 10 a $15 \%$ de área de reserva legal & 3 \\
\hline 5 a $10 \%$ de área de reserva legal & 2 \\
\hline 0 a $5 \%$ de área de reserva legal & 1 \\
\hline 5. PARÂMETRO ÁGUA & 10 \\
\hline 5.1 Subparâmetro fonte d’água & 10 \\
\hline Água de fonte externa com tratamento & 10 \\
\hline Água de poço raso isolado de contaminação & 7,5 \\
\hline Água de poço raso, sem isolamento de contaminação & 5 \\
\hline Água de córrego & 2,5 \\
\hline 6. PARÂMETRO DECLIVIDADE & 10 \\
\hline 6.1 Subparâmetro declividade do terreno & 10 \\
\hline Plano & 10 \\
\hline Suave ondulado & 7,5 \\
\hline Moderado ondulado & 5 \\
\hline Forte ondulado & 2,5 \\
\hline Montanhoso & 0 \\
\hline 7. PARÂMETRO EROSÃO & 4 \\
\hline 7.1 Subparâmetro solo erodido & 4 \\
\hline Não evidenciada & 4 \\
\hline Evidenciada & 0 \\
\hline 8. PARÂMETRO QUEIMADAS & 4 \\
\hline 8.1 Subparâmetro queimada & 4 \\
\hline Não evidenciada & 4 \\
\hline Evidenciada & 0 \\
\hline 9. $\quad$ PARÂMETRO USO DE TERRAS & 2 \\
\hline 9.1 Subparâmetro diversidade de coberturas & 2 \\
\hline Mais que 6 usos e coberturas & 2 \\
\hline De 4 a 6 usos e coberturas & 1 \\
\hline Menos de 4 coberturas & 0 \\
\hline TOTAL & 100 \\
\hline
\end{tabular}

Fonte: Rempel et al. (2012).

\section{RESULTADOS E DISCUSSÃO}

Nas 12 propriedades avaliadas, adota-se o tipo de criação semiextensivo, onde o gado é criado solto em pastagens permanentes ou temporárias, mas ainda recebe trato adicional com rações, farelos, grãos, pasto verde ou silagem em cochos a céu aberto, ou dentro dos galpões de ordenha. Quanto às raças utilizadas, a propriedade 10 somente utiliza Jersey, enquanto que as demais têm rebanho misto de Jersey e Holandesa. Em média, o rebanho de gado bovino é de $28,1(\sigma=16,6)$ cabeças por propriedade, sendo compostas em sua maioria, por vacas em lactação. A produção média diária de leite é de $234,9(\sigma=227,9)$ litros por propriedade (

). 


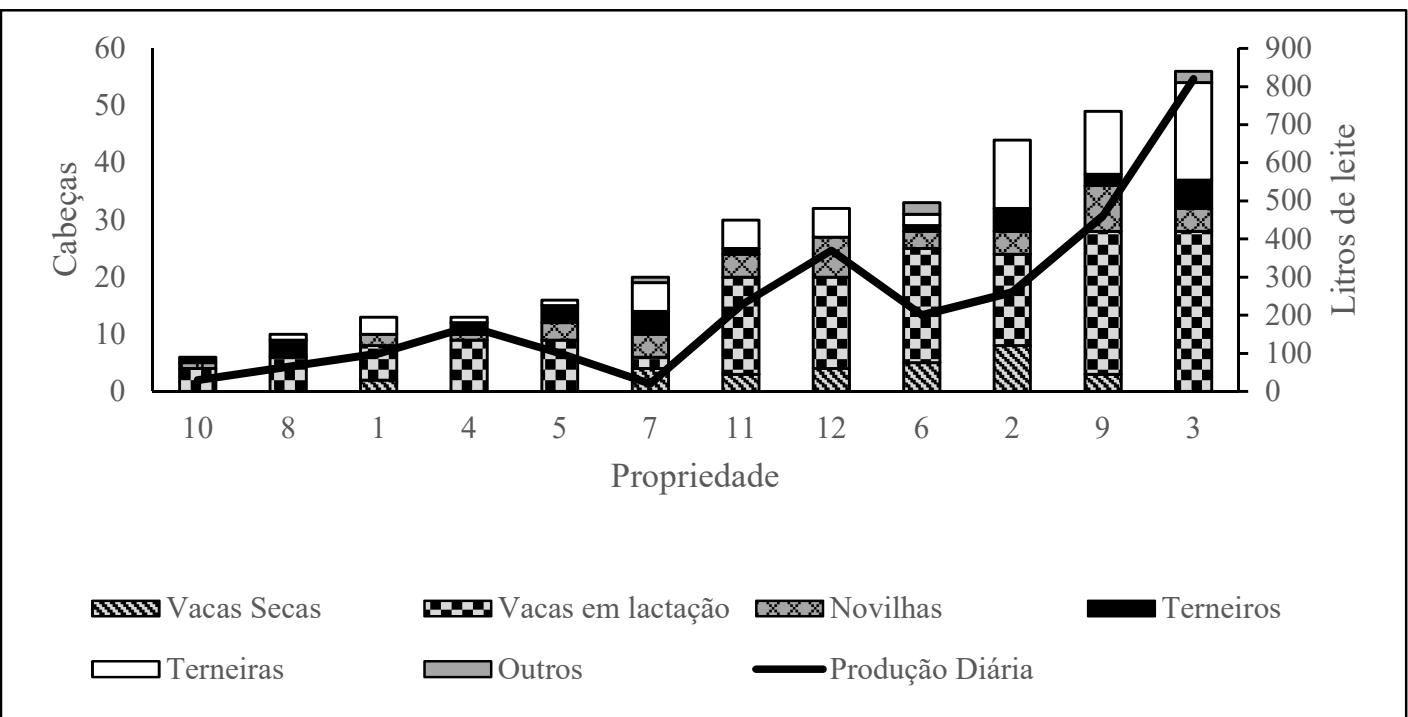

Figura 2: Gráfico da distribuição do rebanho bovino (cabeças) e produção diária de leite (litros) nas doze propriedades estudadas.

A área média das propriedades é de $19,1(\sigma=8,6)$ ha, sendo que todas se situam na faixa com até dois módulos fiscais, considerando que, nos municípios de Colinas e Imigrante, o tamanho do módulo fiscal é de 18 ha (LANDAU et al., 2012). Conforme pode ser observado na

, a ocupação do solo é variável, onde em sete propriedades, a vegetação nativa ocupa área maior do que a destinada para a criação do gado e as culturas agrícolas que servem de alimento para o mesmo. Mas, em média, a vegetação nativa ocupa 42,7 ( $\sigma=20,8) \%$ das propriedades e a área destinada para o gado, 42,0 $(\sigma=20,9) \%$. Ademais, esta vegetação nativa recebe a entrada de gado bovino em $6,4(\sigma=7,2) \%$ de sua área (Figura 4), e em sua maioria, a floresta remanescente é classificada em estádio secundário médio de regeneração $(76,3$ ( $\sigma=16,8) \%$ da área).

No manejo de dejetos sólidos e líquidos, cinco não possuem estrumeiras, quatro propriedades destinam os mesmos a estrumeiras fechadas e com cobertura e três para estrumeiras sem cobertura (Tabela 2). Por outro lado, nove proprietários aguardam pelo menos dois meses de descanso dos dejetos, para então aplicar os mesmos na lavoura, onde dois destes aplicam sem controle, despejando próximo de recursos hídricos. Além disso, quatro propriedades adquirem dejetos de outros locais para aplicar na agricultura, e mesmo assim, ainda utilizam fertilizantes químicos. Quanto à limpeza dos galpões, somente a propriedade 7 limpa semanalmente, enquanto que as demais, limpam duas vezes ao dia; na sala de ordenha, a limpeza é duas vezes por dia para aqueles que a possuem; e na sala de espera, dos três que possuem esta instalação, dois limpam semanalmente e um duas vezes por dia. Convém informar que em todas as propriedades, os animais mortos são enterrados. 


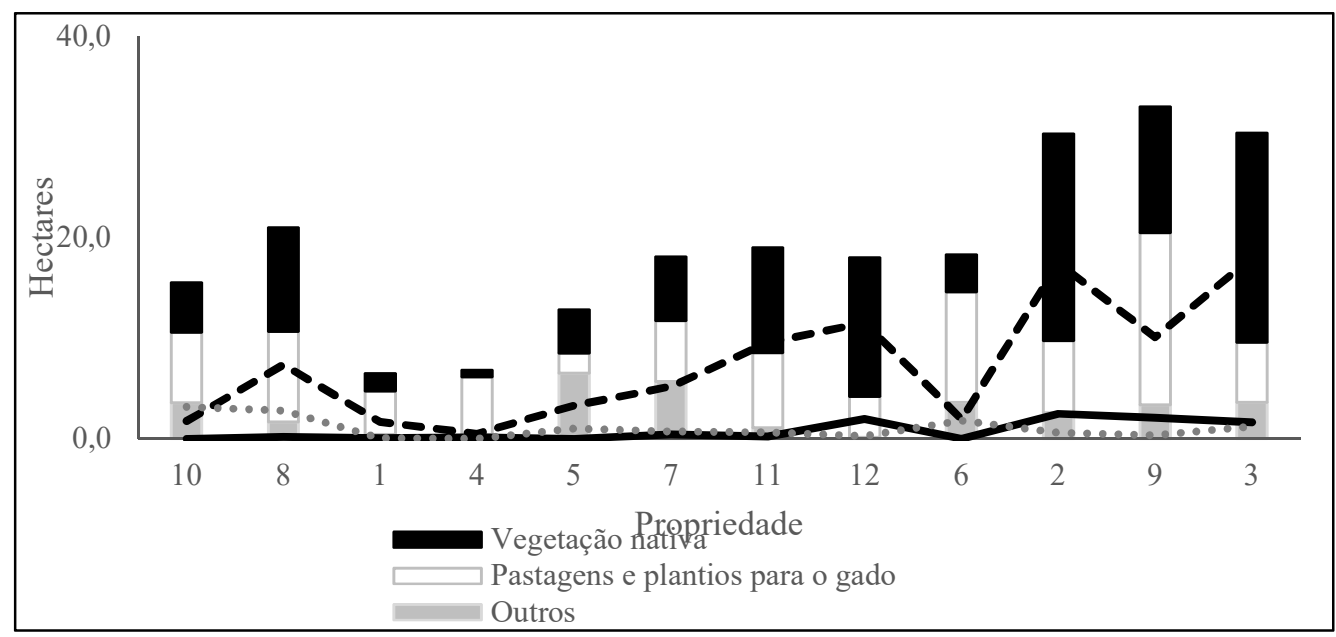

Figura 3: Gráfico do uso do solo (vegetação nativa, pastagens e plantios para o gado e outros - benfeitorias, acessos, floresta industrial, fruticultura e recursos hídricos) nas doze propriedades estudadas em comparação às proporções de estádios sucessionais ocorrentes.

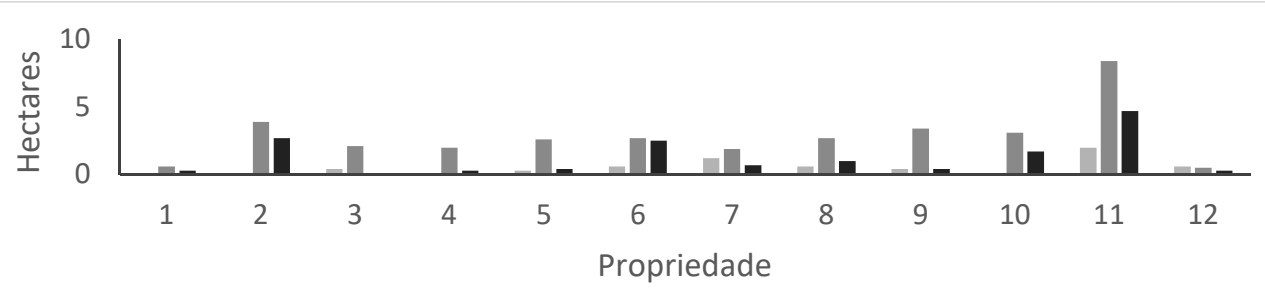

área da propriedade com vegetação nativa e entrada de gado

- Área total da APP

— Área da APP com vegetação nativa e sem entrada do gado

Figura 4: Gráfico da área das propriedades ocupadas por APP (total), APP com vegetação nativa e vegetação nativa com entrada de gado (dentro ou fora da APP) nas doze propriedades estudadas.

Tabela 2: Classificação das propriedades de acordo com o cálculo do índice de sustentabilidade.

\begin{tabular}{|c|c|c|c|c|c|c|c|c|c|c|c|c|}
\hline \multirow[t]{2}{*}{ Parâmetro / subparâmetro } & \multicolumn{12}{|c|}{ Propriedade } \\
\hline & 10 & 8 & 1 & 4 & 5 & 7 & 11 & 12 & 6 & 2 & 9 & 3 \\
\hline $\begin{array}{l}\text { Subparâmetro de armazenamento do } \\
\text { dejeto sólido }\end{array}$ & 3 & 3 & 3 & 3 & 7 & 3 & 10 & 7 & 7 & 10 & 10 & 10 \\
\hline $\begin{array}{l}\text { Subparâmetro de armazenamento do } \\
\text { dejeto líquido }\end{array}$ & 2.5 & 2.5 & 2.5 & 2.5 & 5 & 2.5 & 7.5 & 5 & 5 & 7.5 & 7.5 & 7.5 \\
\hline $\begin{array}{l}\text { Subparâmetro de destinação do dejeto } \\
\text { animal }\end{array}$ & 10 & 10 & 10 & 10 & 10 & 10 & 10 & 10 & 10 & 0 & 10 & 0 \\
\hline Total parâmetro dejetos & 15.5 & 15.5 & 15.5 & 15.5 & 22 & 15.5 & 27.5 & 22 & 22 & 17.5 & 27.5 & 17.5 \\
\hline $\begin{array}{l}\text { Subparâmetro percentual de utilização } \\
\text { antrópica das APPs }\end{array}$ & 0 & 7.5 & 5 & 0 & 0 & 5 & 0 & 0 & 5 & 2.5 & 0 & 5 \\
\hline $\begin{array}{l}\text { Subparâmetro do uso predominante na } \\
\text { APP }\end{array}$ & 4 & 5 & 5 & 3 & 2 & 5 & 4 & 3 & 5 & 5 & 4 & 5 \\
\hline Parâmetro APP & 4 & 12.5 & 10 & 3 & 2 & 10 & 4 & 3 & 10 & 7.5 & 4 & 10 \\
\hline $\begin{array}{l}\text { Subparâmetro utilização de fertilizantes } \\
\text { químicos e agrotóxicos }\end{array}$ & 7.5 & 7.5 & 10 & 5 & 7.5 & 7.5 & 7.5 & 7.5 & 7.5 & 7.5 & 7.5 & 7.5 \\
\hline $\begin{array}{l}\text { Subparâmetro armazenamento de } \\
\text { embalagens de agrotóxicos }\end{array}$ & 5 & 2 & 5 & 3 & 3 & 3 & 3 & 3 & 3 & 3 & 3 & 3 \\
\hline Parâmetro agrotóxicos e fertilizantes & 12.5 & 9.5 & 15 & 8 & 10.5 & 10.5 & 10.5 & 10.5 & 10.5 & 10.5 & 10.5 & 10.5 \\
\hline Parâmetro reserva legal & 10 & 10 & 10 & 3 & 10 & 10 & 10 & 10 & 10 & 10 & 10 & 10 \\
\hline Parâmetro água & 10 & 10 & 5 & 7.5 & 10 & 10 & 10 & 5 & 10 & 10 & 10 & 10 \\
\hline Parâmetro declividade & 5 & 10 & 5 & 7.5 & 5 & 10 & 10 & 2.5 & 10 & 2.5 & 5 & 7.5 \\
\hline Parâmetro erosão & 4 & 4 & 4 & 0 & 0 & 4 & 4 & 4 & 0 & 4 & 4 & 0 \\
\hline Parâmetro queimadas & 4 & 4 & 4 & 4 & 4 & 4 & 4 & 4 & 4 & 4 & 4 & 4 \\
\hline Parâmetro uso de terras & 1 & 1 & 1 & 0 & 1 & 1 & 1 & 0 & 0 & 1 & 0 & 0 \\
\hline PONTUAÇÃO TOTAL & 66 & 76.5 & 69.5 & 48.5 & 64.5 & 75 & 81 & 61 & 76.5 & 67 & 75 & 69.5 \\
\hline
\end{tabular}


Todas as propriedades possuem APP, sendo estas de diversos tipos: margem de arroios e córregos, declividade superior a $45^{\circ}$, entorno de banhados, nascentes e olhos-d'água. Em média $16,1(\sigma=11,3) \%$ da área das propriedades têm seu uso limitado como APP, e destas APP, $41,0(\sigma=26,5) \%$, em média, é somente ocupado por vegetação nativa (Figura 4, Tabela 2).

Quanto aos agrotóxicos e fertilizantes químicos, verifica-se que em somente uma propriedade não se utilizam os mesmos, e nas propriedades que utilizam, em 10 existem cuidados para não aplicar perto de recursos hídricos (Tabela 2). Conforme a entrevista, o agrotóxico mais utilizado é o glifosato (secante de folhas). Relativo ao armazenamento das embalagens, nota-se uma falta de cuidados, onde em nove propriedades, elas são estocadas em depósito coberto, porém junto de outros produtos (sementes, medicamentos veterinários, ferramentas etc.).

Na época do levantamento dos dados, ano de 2014, nenhuma propriedade havia efetuado o Cadastro Ambiental Rural, e apenas uma possuía RL averbada na escritura. Neste viés, Laudares, Silva e Borges (2014), salientam que esta ferramenta eletrônica objetiva a criação de uma base de dados integrada, possibilitando melhor controle ambiental, assim como a possibilidade de planejamento territorial (como a locação de corredor ecológicos); por sua vez, a averbação da RL na matrícula se mostra como mecanismo insuficiente ao controle ambiental. Quanto à cobertura vegetal nativa necessária para a regularização da RL ( $20 \%$ da área total), somente uma propriedade não atende este quesito (Propriedade $4-9,4 \%$ de vegetação nativa), porém, por possuir menos de quatro módulos fiscais, poderá manter a situação desta forma, conforme o artigo 67 da Lei 12.651/2012, desde que não realize novos desmatamentos. Por sua vez, sete propriedades $(1,3,5,7,8,9$ e 10), necessitarão computar APP dentro da RL, o que é permitido pelo artigo 15 do Novo Código Florestal (BRASIL, 2012). Contudo, a inclusão de APP como parte da RL é uma questão polêmica, pois consolida invasões de áreas protegidas e ainda pode ser complicada de fiscalizar (LAUDARES et al., 2014).

Relativo à água consumida pelas pessoas, em nove das propriedades $(2,3,5,6,7,8,9,10$ e 11), a água provém de fonte externa com tratamento (geralmente poços tubulares profundos de Sociedades de Água), em duas (1 e 12), a água é de poço raso sem isolamento de contaminação e em uma (4), a água é de poço raso isolado de contaminação. Conforme as entrevistas, os animais também bebem a água disponível em poças, açudes escavados e nos córregos e arroios que transpassam as propriedades.

A declividade média das propriedades varia consideravelmente, onde quatro são classificadas como moderadamente onduladas (8-13\%), quatro como planas (0-3\%), duas como suave onduladas (3-8\%) e duas como forte onduladas (20-45\%). Conforme apresentado na Tabela 2, em oito propriedades há sinais de erosão do solo; por sua vez, na ocasião das vistorias do estudo, em nenhuma propriedade se evidenciou sinais de queimadas. E ainda, quanto à diversidade de coberturas do solo, sete propriedades $(1,2,5,7,8,10$ e 11) possuem entre 4 e 6 usos e coberturas do solo, e cinco $(3,4,6,9$ e 12), menos de 4 usos e coberturas (Tabela 2). É relevante mencionar, com base em Silva et al. (2015), que uma maior diversidade de coberturas do solo, e consequentemente de tipos de culturas, minimiza os impactos das monoculturas (uso excessivo de fertilizantes e agrotóxicos, compactação do solo), incrementa o controle biológico de pragas e aumenta o leque de produtos para autoconsumo, contribuindo na nutrição do gado e dos humanos. 
Destes resultados, percebe-se uma falta de gestão adequada de dejetos e na prevenção da erosão, bem como o armazenamento inadequado de agrotóxicos. Estas constatações supra estão de acordo com o referido por Scremin et al. (2010), que apontam a criação de gado bovino como impactante do solo, devido à erosão decorrente de pisoteio e sobrepastejo e como sendo uma atividade consideravelmente poluente da água, pela falta de manejo dos dejetos, contaminando recursos hídricos com excesso de matéria orgânica, nitrogênio e um elevado número de contaminantes (antibióticos, hormônios, fertilizantes e pesticidas usados no cultivo de alimentos para o gado). A problemática dos dejetos também é apontada por Rempel et al. (2012), nas propriedades do Vale do Taquari.

Com base nos dados obtidos por entrevistas, vistorias e mapeamento, realizou-se o cálculo da pontuação de sustentabilidade de cada propriedade (Figura 5). O valor médio do índice é de 69,2 ( $\sigma=8,8) \%$, tendo a pior pontuação a propriedade ' 4 ' com $48,5 \%$, e a melhor, a propriedade ' 11 ' com $81 \%$. Cabe mencionar que, conforme os critérios de Rempel et al. (2012), cinco propriedades $(6,7,8,9$ e 11$)$ se enquadraram no conceito 'bom' (entre 70 e 90\%); seis propriedades (1, 2, 3, 5, 10 e 12) no conceito 'regular' (entre 50 e 70\%) e uma (4) no conceito 'ruim', ou seja, entre 20,00 e 50,00 pontos. Os critérios que mais rebaixaram a pontuação foram o manejo de dejetos sólidos e líquidos (cinco propriedades sequer possuem estrumeiras), uso inadequado do solo em APP (conforme pode ser observado na Figura 4, seis propriedades têm menos de $50 \%$ das APP com mata nativa) ou ainda, evidência de erosão no solo (observada em quatro propriedades).

Com base no estudo florístico e fitossociológico das propriedades, constata-se uma riqueza média de 59,5 $(\sigma=14,3)$ espécies, com uma média de 50,4 $(\sigma=12,0)$ nativas e 9,1 $(\sigma=3,4)$ espécies exóticas. Enquanto que a abundância de exóticas é em média de $13,7 \quad(\sigma=6,9) \%$ do total de indivíduos amostrados nas propriedades. Mas, como extremos opostos, cita-se a propriedade '4' com 31 espécies de riqueza geral e 27,9\% de exóticas, e as propriedades '2' e '9', respectivamente, com 78 e 62 espécies, e 16\% e 5,4\% de abundância de exóticas (Figura 6). Consequentemente, há um reflexo no índice de diversidade de Shannon, onde a propriedade ' 4 ' tem o pior índice (2,79 nats), a propriedade '2' o melhor (3,66 nats) e a '9', o 3으 melhor índice (3,52 nats) entre as áreas de estudo. Conforme a metodologia proposta por Markus (2014), adotandose o índice de Shannon para contribuir na pontuação de sustentabilidade de propriedades produtoras de leite, somente uma propriedade está no conceito 'bom' ( $H^{\prime}$ entre 2,25 e 3 nats), que é a propriedade '4'. Por outro lado, as demais 11 estão no conceito 'excelente' ( $\mathrm{H}^{\prime}$ maior que 3 nats). 


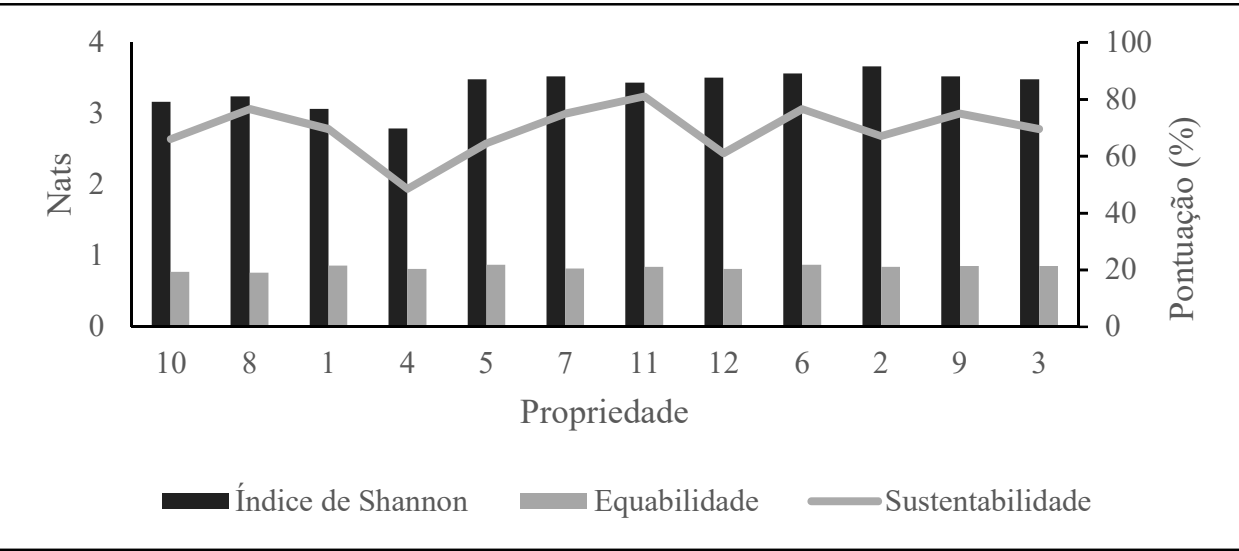

Figura 5: Gráfico comparativo entre a pontuação de sustentabilidade (\%) e os índices de diversidade de Shannon e Equabilidade de Pielou (nats), nas 12 propriedades estudadas. Fonte: Zerwes (2016).

Na Figura 5 são demonstrados os índices de diversidade de Shannon e de equabilidade de Pielou, cuja média é respectivamente de $3,37(\sigma=0,25)$ e $0,83(\sigma=0,04)$ nats. Visando comparar os índices de diversidade e sustentabilidade, Zerwes (2016) havia constatado uma correlação forte positiva $\left(r^{2}=0,80\right)$ e significativa $(p=<0,01)$ entre o índice de Shannon e a pontuação de sustentabilidade; contudo, no presente estudo (

Tabela 3), a correlação foi média $\left(r^{2}=0,544\right)$ e não significativa para um $\alpha=0,05(p=0,067)$. Além disso, neste estudo, observou-se também uma correlação positiva e significativa entre o tamanho do rebanho de gado e o $\mathrm{H}^{\prime}\left(\mathrm{r}^{2}=0,660 \mathrm{p}=0,019\right)$, mas não entre o tamanho do rebanho e a pontuação de sustentabilidade $\left(r^{2}=0,237 p=0,457\right)$. Esta diferença entre os estudos se deve ao modo como a pontuação de sustentabilidade foi calculada, onde no presente utilizou-se os parâmetros e subparâmetros exatamente iguais aos de Rempel et al. (2012), e em Zerwes (2016), foi feita uma adaptação para incluir o subparâmetro de água consumida pelo gado. Desta forma, o resultado não desmerece a importância do uso de índices de diversidade para o diagnóstico de sustentabilidade e da importância da fitossociologia não somente para compreender a estrutura das comunidades vegetais, e sim, também como uma importante ferramenta para avaliação de impactos ambientais e fornecimento de uma base de dados para a restauração de ambientes degradados.

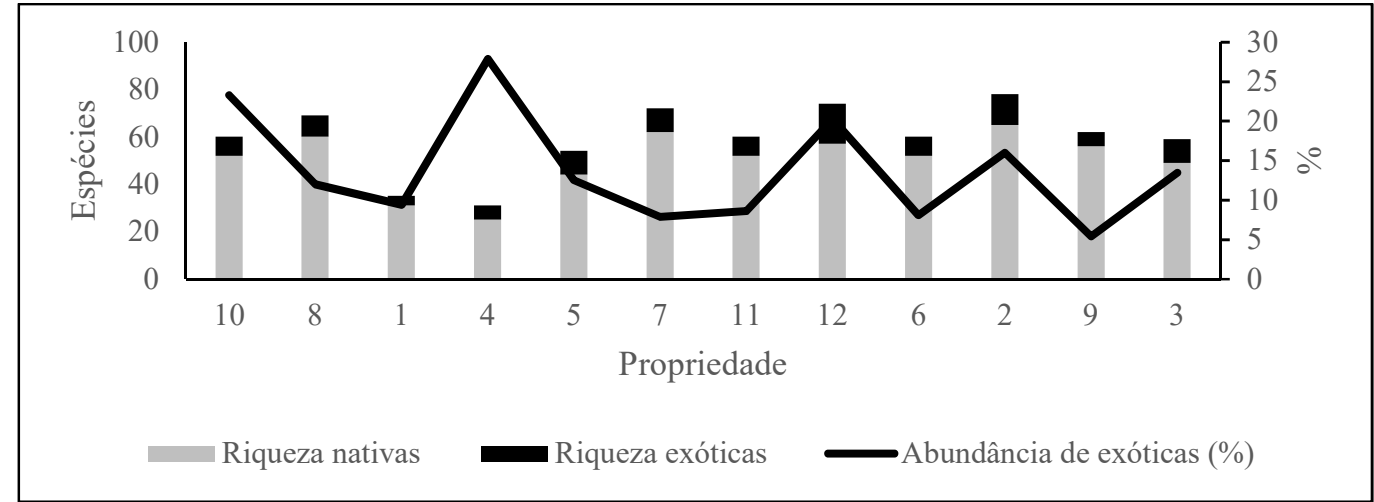

Figura 6: Gráfico da riqueza de espécies (nativas e exóticas) e a abundância de exóticas (\%) nas 12 propriedades estudadas. Fonte: Zerwes (2016).

Tabela 3: Correlação linear entre tamanho do rebanho, pontuação de sustentabilidade, índices de diversidade e outros parâmetros da vegetação arbórea ocorrente nas doze propriedades estudadas (triângulo inferior) e nível de significância 
(p) da correlação linear (triângulo superior). (Legenda: TR - tamanho do rebanho; PS - pontos de sustentabilidade; $H^{\prime}$ índice de diversidade de Shannon; RI - riqueza; EX - abundância de exóticas; IN - percentual de parcelas em estágio inicial; ME - percentual de parcelas em estágio médio; AV - percentual de parcelas em estágio avançado ou primário; DEG - percentual de parcelas com sub-bosque degradado; E' - equabilidade; Ds - índice de Simpson; UA's - parcelas realizadas; célula hachurada - forte a média correlação positiva; célula pintada de cinza - forte a média correlação negativa; célula com letra em negrito $-p$ significativo $\alpha=0,05)$.

\begin{tabular}{|c|c|c|c|c|c|c|c|c|c|c|c|c|}
\hline & TR & PS & $\mathrm{H}^{\prime}$ & $\mathbf{R I}$ & EX & IN & ME & AV & Deg & $E^{\prime}$ & Ds & UA's \\
\hline TR & - & 0.457 & 0.019 & 0.227 & 0.283 & 0.179 & 0.894 & 0.721 & 0.321 & 0.096 & 0.010 & 0.420 \\
\hline PS & 0.237 & - & 0.067 & 0.148 & 0.000 & 0.392 & 0.926 & 0.703 & 0.097 & 0.638 & 0.049 & 0.257 \\
\hline $\mathrm{H}^{\prime}$ & 0.6.60 & 0.5. & - & 0.002 & 0.057 & 0.040 & 0.475 & 0.924 & 0.050 & 0.195 & 0.000 & 0.048 \\
\hline RI & 0.377 & 0.444 & 0.98 & - & 0.446 & 0.414 & 0.136 & 0.386 & 0.227 & 0.496 & 0.086 & 0.000 \\
\hline EX & -0.338 & -0.862 & -0.562 & -0.243 & - & 0.056 & 0.348 & 0.147 & 0.024 & 0.089 & 0.014 & 0.786 \\
\hline IN & -0.416 & -0.272 & -0.598 & -0.260 & 0.564 & - & 0.253 & 0.021 & 0.179 & 0.046 & 0.017 & 0.827 \\
\hline ME & 0.043 & -0.030 & 0.229 & 0.456 & 0.298 & 0.358 & - & 0.000 & 0.863 & 0.221 & 0.992 & 0.095 \\
\hline AV & 0.116 & 0.123 & 0.031 & -0.276 & -0.446 & -0.653 & -0.941 & - & 0.745 & 0.082 & 0.453 & 0.219 \\
\hline DEG & 0.313 & 0.501 & 0.576 & 0.377 & -0.644 & -0.416 & 0.056 & 0.105 & - & 0.272 & 0.115 & 0.669 \\
\hline$E^{\prime}$ & 0.502 & 0.152 & 0.402 & -0.218 & -0.512 & -0.585 & -0.381 & 0.521 & 0.345 & - & 0.016 & 0.181 \\
\hline Ds & -0.705 & -0.578 & -0.913 & -0.516 & 0.684 & 0.669 & -0.003 & -0.240 & -0.479 & -0.676 & - & 0.370 \\
\hline UA's & 0.257 & 0.356 & 0.580 & 0.91- & -0.088 & -0.071 & 0.504 & -0.383 & 0.138 & -0.414 & -0.285 & - \\
\hline
\end{tabular}

Elaborado no Past 2.17c.

Com base nas constatações supracitadas, pode-se sugerir as medidas necessárias para que cada propriedade rural estudada se adeque e incremente seu índice de sustentabilidade. Para tanto, criou-se a Tabela 4, onde estão indicadas as medidas para cada propriedade, cuja prioridade é sugerida para ações impactantes que rebaixam o índice de sustentabilidade e que são de fácil solução, evitando impactos de relevância à água e solo, como o manejo de dejetos, fertilizantes e agrotóxicos. Por sua vez, medidas que demandam mais tempo para serem resolvidas, como a recomposição de APP e reserva legal, bem como a introdução de espécies vegetais nativas para incremento de diversidade, foram colocadas com um nível de prioridade menor. Convém mencionar que a proposição de prioridades no atendimento de medidas mitigadoras não significa um juízo de importância, mas sim, uma sugestão de resolução de problemas, pois, sanando-se problemas mais simples, haverá maior disponibilidade de tempo e recursos para adentrar nas medidas complexas.

Com base na metodologia supra, é possível diagnosticar a situação atual das propriedades quanto à sustentabilidade, e com isso, ter diretrizes para o planejamento de medidas a serem adotadas. Mas, como é uma lista considerável de dados, isto demanda uma análise detalhada das matrizes de dados e também um julgamento de prioridades que pode ter um grau de subjetividade, é de suma importância a criação de uma metodologia mais ágil e objetiva para detecção dos pontos relevantes, ou seja, um software de avaliação de sustentabilidade.

Tabela 4: Medidas mitigadoras e compensatórias propostas para cada propriedade rural estudada (Legenda: + alta urgência; = média urgência; - sem urgência).

\begin{tabular}{|c|c|c|c|c|c|c|c|c|c|c|c|c|}
\hline \multirow[b]{2}{*}{ Medida proposta } & \multicolumn{12}{|c|}{ Propriedade } \\
\hline & 1 & 2 & 3 & 4 & 5 & 6 & 7 & 8 & 9 & 10 & 11 & 12 \\
\hline $\begin{array}{l}\text { Aplicar fertilizantes e agrotóxicos de forma controlada, evitando pontos } \\
\text { próximos à recursos hídricos e residências }\end{array}$ & & & & + & & & & & & & & \\
\hline Construir um depósito adequado para os agrotóxicos & & & & & & & & + & & & & \\
\hline $\begin{array}{l}\text { Construir um sistema para isolamento da água de poço, para evitar } \\
\text { contaminação }\end{array}$ & + & & & & & & & & & & & + \\
\hline Construir uma cobertura para a estrumeira & $=$ & & & $=$ & $=$ & $=$ & $=$ & $=$ & & $=$ & & $=$ \\
\hline Construir uma estrumeira & + & & & + & & & + & + & & + & & \\
\hline
\end{tabular}




\begin{tabular}{|c|c|c|c|c|c|c|c|c|c|c|c|c|}
\hline $\begin{array}{l}\text { Controlar a erosão com redução da quantidade de cabeças por área e ciclo } \\
\text { de troca constante de piquetes }\end{array}$ & - & - & $=$ & $=$ & $=$ & $=$ & - & - & - & - & - & - \\
\hline Diversificar os usos do solo & - & - & $=$ & $=$ & - & $=$ & - & - & $=$ & - & - & $=$ \\
\hline $\begin{array}{l}\text { Introduzir mudas de espécies arbóreas nativas para aumentar a diversidade } \\
\text { local }\end{array}$ & & & & - & & & & & & & & \\
\hline $\begin{array}{l}\text { Realizar o tratamento da água proveniente de poço raso, ao menos para } \\
\text { consumo humano }\end{array}$ & + & & & $=$ & & & & & & & & + \\
\hline Recompor reserva legal & & & & - & & & & & & & & \\
\hline Recompor vegetação em APP & $=$ & $=$ & $=$ & + & + & $=$ & $=$ & $=$ & - & $=$ & + & + \\
\hline
\end{tabular}

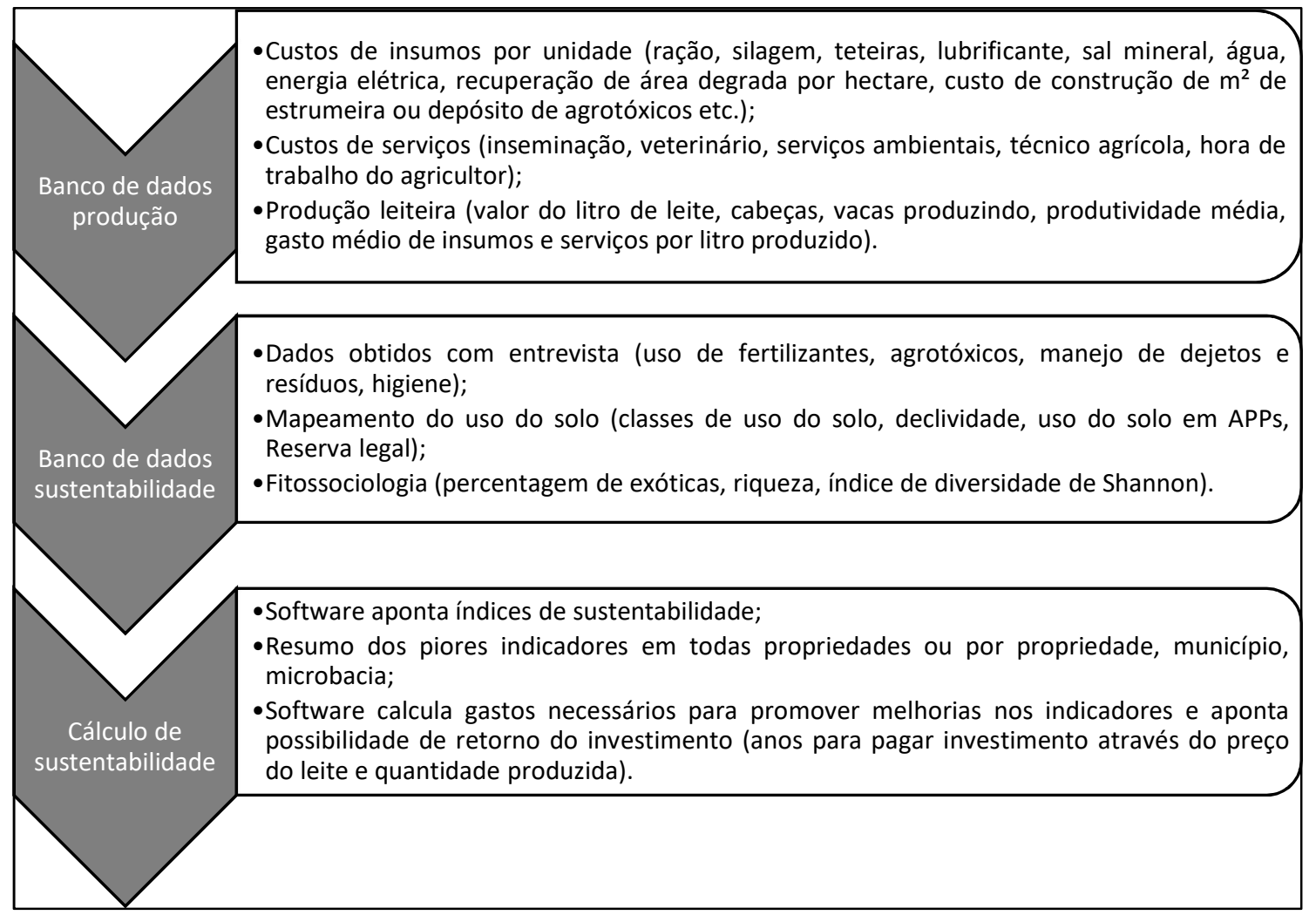

Figura 7: Fluxograma do software sugerido para o diagnóstico e gestão da sustentabilidade de propriedades produtoras de leite.

Softwares com tal finalidade já existem, podendo-se citar o FPS - Fazenda Pantaneira Sustentável da Embrapa Informática Agropecuária (LIMA et al., 2011); O ECO OBRA (OLIVEIRA et al., 2012); e o APOIANovoRural (RODRIGUES et al., 2003), este último sendo um conjunto de planilhas eletrônicas. Outro método que utiliza planilhas e gráficos para diagnóstico de sustentabilidade, é o Barômetro da Sustentabilidade, que foi concebido por Prescott-Allen (1996) e recentemente utilizado em assentamentos rurais no Pará (SILVA et al., 2016).

Uma sugestão é a criação de um software dividido em três módulos: banco de dados da produção leiteira e de custos envolvidos na produção ou promoção de melhorias ambientais, banco de dados de sustentabilidade e um módulo de cálculo de sustentabilidade do empreendimento e dos investimentos necessários para as melhorias ambientais necessárias. Este software teria que gerar resultados por propriedade selecionada, município, microbacia ou ainda, todas as propriedades do projeto juntas. Um fluxograma da sugestão de software, segue apresentada na Figura 7.

\section{CONCLUSÕES}


O diagnóstico apontou que seis propriedades podem ser enquadradas como tendo sustentabilidade no conceito 'regular', cinco no conceito 'bom' e uma no conceito 'ruim'. A diminuição dos índices se deve principalmente a problemas no manejo de dejetos sólidos e líquidos, uso inadequado do solo em APP e evidência de erosão. Dentre as medidas mitigadoras, sugere-se a construção de estrumeiras cobertas, tratamento da água de consumo, recomposição gradual das APP e controle dos pontos de erosão.

Neste estudo, se constatou correlação média positiva, porém não significativa $(\alpha=0,05)$, entre o índice de diversidade de Shannon e a pontuação de sustentabilidade, e ainda, uma correlação média positiva e significativa entre o tamanho do rebanho e o índice de diversidade de Shannon. Onze propriedades se enquadraram como tendo excelente diversidade, e uma, boa diversidade; para esta última, sugere-se a introdução de espécies nativas não mais ocorrentes na propriedade, a fim de incrementar a diversidade local. Para tornar o diagnóstico mais ágil e diminuir a subjetividade da mesma, sugere-se a construção de software, que poderá também ser adaptado para outras atividades agropecuárias.

AGRADECIMENTOS: Aos bolsistas do grupo de pesquisa, pela obtenção, tabulação e fornecimento dos dados das propriedades leiteiras; à CAPES pelo fornecimento de bolsa-taxa ao primeiro autor e aos produtores rurais que disponibilizaram suas propriedades e seu tempo à pesquisa.

\section{REFERÊNCIAS}

BRASIL. Lei n. 12.651. Dispõe sobre a proteção da vegetação nativa; altera as Leis $n$ ㅇs 6.938 , de 31 de agosto de 1981, 9.393, de 19 de dezembro de 1996, e 11.428, de 22 de dezembro de 2006; revoga as Leis nos 4.771, de 15 de setembro de 1965, e 7.754, de 14 de abril de 1989, e a Medida Provisória no 2.166-67, de 24 de agosto de 2001, e dá outras providências. Brasília: DOU, 2012.

CIH-UNIVATES. Centro de Informações. Hidrometeorológicas da UNIVATES: Informações hidrometeorológicas. Lajeado: UNIVATES, 2012.

CPRM. Companhia de Pesquisa de Recursos Minerais. Mapa geológico do estado do Rio Grande do Sul. Porto Alegre: Ministério de Minas e Energia, 2006.

FISZON, J. T.. Causas antrópicas. In: RAMBALDI, D. M.; OLIVEIRA, D. A. S.. Fragmentação de ecossistemas: causas, efeitos sobre a biodiversidade e recomendações de políticas públicas. Brasília: Ministério do Meio Ambiente, 2003. p.65102.

HAMMER, O.; HARPER, D. A. T.; RYAN, P. D.. PAST: Paleontological statistics software package for education and data analysis. Palaeontologia Electronica, 2001.

IBGE. Instituto Brasileiro de Geografia e Estatística. Vegetação: Caxias do Sul SH.22-V-D. Florianópolis: IBGE, 2003.

IBGE. Instituto Brasileiro de Geografia e Estatística. Censo Agropecuário 2006: Brasil, grandes regiões e unidades da Federação. Rio de Janeiro: Ministério do Planejamento, Orçamento e Gestão, 2006.
IBGE. Instituto Brasileiro de Geografia e Estatística. Manual Técnico da Vegetação Brasileira: sistema fitogeográfico inventário das formações florestais e campestres técnicas e manejo de coleções botânicas procedimentos para mapeamentos. 2 ed. Rio de Janeiro: IBGE, 2012.

IBGE. Instituto Brasileiro de Geografia e Estatística. Rio Grande do Sul: Imigrante, 2014.

INDE. Infraestrutura Nacional de Dados Espaciais. Visualizador da INDE. 2016.

LANDAU, E. C.; HIRSCH, A.; CRUZ, R. K. M.; PIMENTA, F.. Variação geográfica do tamanho dos módulos fiscais no Brasil. Sete Lagoas: Embrapa Milho e Sorgo, 2012.

LAUDARES, S. S. A.; SILVA, K. G.; BORGES, L. A. C.. Cadastro Ambiental Rural: uma análise da nova ferramenta para regularização ambiental no Brasil. Desenvolvimento e Meio Ambiente, Curitiba, v.31, p.111-122, 2014. DOI: http://dx.doi.org/10.5380/dma.v31i0.33743

LIMA, H. P.; MASSRUHA, S. M. F. S.; ABREU, U. G. P.; SANTOS, S. A.. Webfuzzy e fuzzygen - ferramentas para modelagem fuzzy: aplicação na sustentabilidade das fazendas do pantanal. In: CONGRESSO BRASILEIRO DE AGROINFORMÁTICA, 8. Anais. Florianópolis: UFSC; Pelotas: UFPel, 2011.

MARKUS, E.. Estrutura arbórea da mata ciliar como indicador ambiental em propriedades leiteiras com floresta estacional decidual. Dissertação (Mestrado em Ambiente e 
Desenvolvimento) - Universidade do Vale do Taquari, Lajeado, 2014.

OLIVEIRA, J. A. C.; SPOSTO, R. M.; BLUMENSCHEIN, R. N.. Ferramenta para avaliação da sustentabilidade ambiental na fase de execução de edifícios no Distrito Federal. Bauru: GEPROS, 2012.

PACCALIN, J.; GALANTIER, M.. Valor nutritivo do leite e dos produtos lácteos. In: LUQUET, F. M.; LINCZOWSKI, Y. B.. O leite: a qualidade na indústria de laticínios. Algueirão-Mem Martins: Publicações Europa-América, 1985. p.119-154.

PRESCOTT-ALLEN, R.. Barometer of Sustainability: what it's for and how to use it. Gland: IUCN, 1996.

REMPEL, C.; ECKHARDT, R. R.; JASPER, A.; SCHULTZ, G.; HILGERT, Í. H.; BARDEN, J. E.. Proposta metodológica de avaliação da sustentabilidade ambiental de propriedades produtoras de leite. Tecno-lógica, Santa Cruz do Sul, v.16, n.1, p.48-54, 2012.

RODRIGUES, G. S.; CAMPANHOLA, C.. Sistema integrado de avaliação de impacto ambiental aplicado a atividades do Novo Rural. Pesquisa Agropecuária Brasileira, Brasília, v. 38, n. 4, p. 445-451, 2003.
SCREMIN, A. P.; KEMERICH, P. D. C.. Impactos ambientais em propriedade rural de atividade mista. Disciplinarium Scientia Série Ciências Naturais e Tecnológicas, Santa Maria, v.10, n.1, p.126-148, 2010.

SILVA, V. R.; SILVA, M. M.; PEREIRA, M. C. B.. Pluriatividade e sustentabilidade em comunidades rurais do semiárido nordestino. Desenvolvimento e Meio Ambiente, Curitiba, v.35, p.349-366, 2015. DOI: http://dx.doi.org/10.5380/dma.v35i0.40504

SILVA, V. C. S.; VIEIRA, I. C. G.. Barômetro da Sustentabilidade aplicado a assentamentos rurais do leste do Estado do Pará, Brasil. Desenvolvimento e Meio Ambiente, Curitiba, v.36, p.201-221, 2016. DOI: http://dx.doi.org/10.5380/dma.v36i0.39957

VECCHIONE, G.. EU rural policy: proposal and application of an agricultural sustainability index. Universidade de Monique: MPRA, 2010.

ZERWES, C. M.. Estrato arbóreo de fragmentos de floresta estacional decidual submontana em propriedades produtoras de leite: uso de dados fitossociológicos para diagnóstico de sustentabilidade. Dissertação (Mestrado em Ambiente e Desenvolvimento) - Universidade do Vale do Taquari, 2016.

A CBPC - Companhia Brasileira de Produção Científica (CNPJ: 11.221.422/0001-03) detém os direitos materiais desta publicação. Os direitos referem-se à publicação do trabalho em qualquer parte do mundo, incluindo os direitos às renovações, expansões e disseminações da contribuição, bem como outros direitos subsidiários. Todos os trabalhos publicados eletronicamente poderão posteriormente ser publicados em coletâneas impressas sob coordenação da Sustenere Publishing, da Companhia Brasileira de Produção Científica e seus parceiros autorizados. Os (as) autores (as) preservam os direitos autorais, mas não têm permissão para a publicação da contribuição em outro meio, impresso ou digital, em português ou em tradução. 